\title{
Inventarisasi Jenis Pohon Pada Cagar Alam Gunung Ambang, Sulawesi Utara
}

\author{
Akbar Arafah Emboa*, Roni Koneria, Saroyoa, Adelfia Papua \\ aJurusan Biologi, FMIPA, Unsrat, Manado
}

\begin{tabular}{l}
\hline K A T A K U N C I \\
\hline inventarisasi \\
pohon \\
Cagar Alam Gunung Ambang
\end{tabular}

\begin{abstract}
A B S T R A K
Pohon sebagai penyusun utama kawasan hutan berperan penting dalam pengaturan tata air, cadangan plasma nutfah, penyangga kehidupan, sumber daya pembangunan dan sumber devisa Negara. Peranan pohonpohon dalam komunitas hutan semakin sulit dipertahankan mengingat tekanan masyarakat terhadap kelompok tumbuhan dari waktu ke waktu terus meningkat.Penelitian ini bertujuan untuk mengkaji jenis-jenis pohon yang berada di kawasan Cagar Alam Gunung Ambang, Sulawesi Utara. Metode penelitian yang digunakan yaitu metode garis berpetak yang merupakan modifiksi dari metode petak atau plot ganda dan metode jalur. Tipe habitat yang dijadikan titik pengambilan sampel adalah hutan primer dan hutan sekunder. Hasil pengamatan diperoleh sebanyak 38 jenis pohon penyusun hutan di Gunung Ambang yang termasuk dalam 22 suku. Pada hutan primer disusun oleh 37 jenis dan 22 suku, sedangkan pada hutan sekunder terdiri dari 28 jenis yang termasuk dalam 18 suku. Jenis pohon yang mendominasi setiap lokasi penelitian yaitu suku Magnoliaceae dan Arecaceae.
\end{abstract}

\begin{tabular}{l}
\hline K E Y W O R D S \\
\hline inventory \\
tree \\
Gunung Ambang nature reserve
\end{tabular}

A B S T R A C T
Tree as the main constituent of forests play an important role in water
regulation, germplasm reserves, life support, development resources and
the country's foreign exchange resources. The role of trees in the forest
communities are difficult to be sustained because the people pressure
increase on the trees day by day. This study aims to assess the types of
trees that are in the nature reserve area of Gunung Ambang, North
Sulawesi. The method used is the line transect plots that is modified from
the plot method or a double plot and track method. The type of habitat
that is used as the starting sampling point is the primary forests and
secondary forests. Result of observations showed that Gunung Ambang is
composed by 38 species of plant in 22 family. In the primary forest
composed by 37 species and 22 Family, whereas in secondary forest
consists of 28 species in 18 family. Types of trees that dominate each
research location are Family Magnoliaceae and Family Arecaceae.

TERSEDIA ONLINE

5 Juli 2015

\section{Pendahuluan}

Indonesia merupakan daerah yang memiliki hutan hujan tropis yang sangat kompleks dengan ciri yang utama adalah pepohonan dengan berbagai ukuran.Kanopi hutan menyebabkan iklim mikro yang berbeda dengan keadaan di luarnya (Whitmore, 1998). Hutan hujan tropis terkenal karena adanya pelapisan atau stratifikasi pohon, diantaranya yaitu lapisan atas (tingkat A) terdiri dari pepohonan setinggi 31-45 m dengan tajuk yang diskontinu, lapisan pepohonan kedua (tingkat B) terdiri dari pohon dengan tinggi sekitar 20-30 m dengan tajuk yang kontinu sehingga membentuk kanopi, lapisan pepohonan ketiga (tingkat C) terdiri

*Corresponding author: Jurusan Biologi FMIPA UNSRAT, Jl. Kampus Unsrat, Manado, Indonesia 95115; Email address: akbarembo@yahoo.co.id Published by FMIPA UNSRAT (2015) 
dari pepohonan dengan tinggi sekitar 4-19 m cenderung membentuk lapisan yang rapat. Selain lapisan pepohonan juga terdapatvsemak belukar yang tingginya kurang dari $10 \mathrm{~m}$ dan yang terakhir adalah lapisan terna yang terdiri dari tetumbuhan yang lebih kecil yang merupakan kecambah dari pepohonan yang lebih besar dari bagian atas atau jenis terna (Ewusie, 1990).

Cagar Alam Gunung Ambang yang terletak di antara Kabupaten Bolaang Mongondow dan Minahasa Selatan merupakan salah satu kawasan konservasi hutan yang berada di Sulawesi Utara. Permasalahan yang umumnya terjadi di kawasan Cagar Alam Gunung Ambang berupa minimnya sarana dan prasarana penunjang pengelolaan yang terbatas, illegal logging dan pencurian hasil hutan non kayu, okupasi kawasan hutan untuk pertanian, perburuan satwa endemik dan dilindungi serta dimusim kemarau kawasan ini relatif rentan terhadap kebakaran hutan (BKSDA SULUT, 2009). Banyaknya kegiatan manusia yang dapat merusak kawasan Cagar Alam ini dapat menyebabkan perubahan komposisi serta struktur vegetasi dilihat dari profil vegetasi hutan. Keadaan seperti ini dapat menyebabkan terjadinya ketidakseimbangan pada ekosistem hutan.

Saat ini publikasi tentang kondisi alami hutan di Cagar Alam Gunung Ambang masih sedikit, karena kurangnya informasi serta data-data penelitian, sehingga perlu dilakukan inventarisasi dan pengkajian jenis-jenis pohon di Cagar Alam Gunung Ambang, Kabupaten Bolaang Mongondow Timur.

\section{Metode}

\subsection{Waktu dan tempat penelitian}

Penelitian dilakukan pada bulan Juni sampai Agustus 2011, bertempat di Cagar Alam Gunung Ambang Bolaang, Kabupaten Mongondow Timur (Gambar 1).

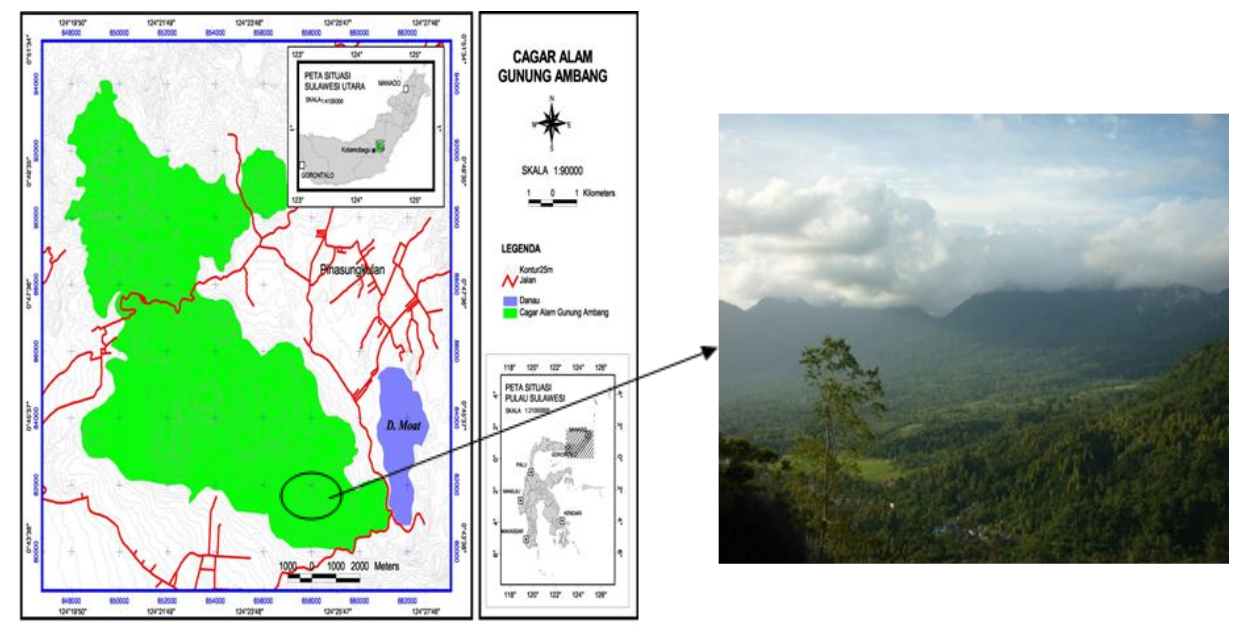

Gambar 1. Peta Lokasi Penelitian (WCS SULUT, 2007)

\subsection{Alat dan bahan}

Alat-alat yang digunakan pada penelitian ini adalah rol meter, kamera, kompas, altimeter, GPS (Global Positioning Sistem), dan higrometer.

\subsection{Teknik pengambilan sampel}

Pengamatan dan pengambilan sampel dilakukan di Cagar Alam Gunung Ambang dengan menggunakan metode garis berpetak yang merupakan modifiksi dari metode petak/plot ganda dan metode jalur. Pemasangan plot untuk pengambilan sampel dilakukan pada dua tipe habitat yaitu Hutan Sekender dan Hutan Primer. Pada setiap tipe habitat terdapat dua plot dengan panjang $100 \mathrm{~m}$ dan lebar $5 \mathrm{~m}$ serta jarak antara kedua plot sepanjang $100 \mathrm{~m}$. Sampling dilakukan ditiap plot dalam tipe habitat (Hutan Sekunder dan Hutan Primer) berdasarkan arah mata angin.

Setiap jenis pohon yang berada di lokasi pengambilan sampel (plot) dipetakan dan diidentifikasi. Untuk penamaan jenis tumbuhan (pohon) atau setiap individu yang diidentifikasi, menggunakan buku kunci determinasi tumbuhan atau buku Flora van N.O. Celebes (Koorders, 1922) dan Cronquist (1981). Data yang diperoleh kemudian dianalisis secara deskriptif.

\section{Hasil dan Pembahasan}

Jenis pohon yang ditemukan di hutan Gunung Ambang sebanyak 38 jenis dengan 210 individu yang termasuk dalam 22 suku. Jenis yang paling banyak ditemukan adalah Elmerilia ovalis yang termasuk dalam suku Magnoliaceae, kemudian dikuti oleh Ficus variegata yang termasuk suku Moraceae.

\subsection{Hutan Primer}

Pada hutan primer didapatkan sebanyak 37 jenis dan 113 individu pohon dari 22 suku (Tabel 1). Jenis pohon yang dominan pada hutan primer 
adalah Ficus variagata. Plot satu pada hutan primer jenis pohon yang mendominasi yaitu Suku

Arecaceae yaitu Marga Areca, Arenga dan Figafetta serta dari marga Palaquium dan Adinandra.

Tabel 1. Jenis pohon yang ditemukan pada hutan primer di Gunung Ambang, Sulawesi Utara

\begin{tabular}{|c|c|c|c|c|c|}
\hline No & Nama jenis & Nama lokal & Suku & $\sum$ individu & $\%$ \\
\hline 1 & Adinandra celebica & Adinandra & Theaceae & 3 & 2.65 \\
\hline 2 & Adinandra sp. & Topad & Theaceae & 6 & 5.31 \\
\hline 3 & Agathis sp. & Toayab & Araucariaceae & 1 & 0.88 \\
\hline 4 & Aleurites moluccana & Kemiri & Euphorbiaceae & 3 & 2.65 \\
\hline 5 & Allaenthus luzonicus & Bouli & Moraceae & 2 & 1.77 \\
\hline 6 & Areca cetachu & Palem & Arecaceae & 3 & 2.65 \\
\hline 7 & Areca vestiaria & Pinang yaki & Arecaceae & 3 & 2.65 \\
\hline 8 & Arenga pinnata & Pohon Aren & Arecaceae & 4 & 3.54 \\
\hline 9 & Artocarpus sp. & Nangka Hutan & Moraceae & 1 & 0.88 \\
\hline 10 & Bambusa sp. & Bambu & Poaceae & 1 & 0.88 \\
\hline 11 & Calamus sp. & Rotan & Arecaceae & 4 & 3.54 \\
\hline 12 & Calliandra callothyrus & Kaliandra & Caesalpiniaceae & 1 & 0.88 \\
\hline 13 & Casuarinasp. & Cemara & Casuarinaceae & 1 & 0.88 \\
\hline 14 & Cinnamomum burmannii & Kayu Manis & Lauraceae & 2 & 1.77 \\
\hline 15 & Cyathocalyx sp & Durian Hutan & Bombaceaea & 1 & 0.88 \\
\hline 16 & Cyntandra sp. & Monanow & Gesneriaceae & 1 & 0.88 \\
\hline 17 & Dillenia serrata & Dangin & Dilleniaceae & 2 & 1.77 \\
\hline 18 & Elmerilia ovalis & Cempaka & Magnoliaceae & 3 & 2.65 \\
\hline 19 & Endospermum pelatum & Mapopo & Euphorbiaceae & 2 & 1.77 \\
\hline 20 & Endospermum sp & Bukuan & Euphorbiaceae & 1 & 0.88 \\
\hline 21 & Eugeniasp. & Jambu Air Hutan & Myrtaceae & 1 & 0.88 \\
\hline 22 & Ficus sp. & Beringin & Moraceae & 1 & 0.88 \\
\hline 23 & Ficus variegata & Aga Hutan & Moraceae & 5 & 4.42 \\
\hline 24 & Koordersiodendron pinnatum & Bugis & Anacardiaceae & 2 & 1.77 \\
\hline 25 & Laportea $s p$ & Sosoro Hutan & Urticaceae & 1 & 0.88 \\
\hline 26 & Myristica fatua & Pala Hutan & Myristicaceae & 3 & 2.65 \\
\hline 27 & Myristicasp. & Lokukuyu & Myristicaceae & 1 & 0.88 \\
\hline 28 & Nephelium $s p$ & Rambutan Hutan & Sapindaceae & 1 & 0.88 \\
\hline 29 & Palaquium obovatum & Lungkap & Sapindaceae & 7 & 6.19 \\
\hline 30 & Palaquium obtusifolium & Nantu & Sapindaceae & 1 & 0.88 \\
\hline 31 & Pigafetta filaris & Wanga & Arecaceae & 7 & 6.19 \\
\hline 32 & Pometiasp. & Matoa Hutan & Sapindaceae & 1 & 0.88 \\
\hline 33 & Pterocarpus indicus & Linggua Hutan & Fabaceae & 1 & 0.88 \\
\hline 34 & Pterospermum celebecum & Bayuk & Sterculiaceae & 1 & 0.88 \\
\hline 35 & Saurauia sp. & Pasi & Actinidiaceae & 4 & 3.54 \\
\hline 36 & Spondias pinnata & Uribat & Anacardiaceae & 1 & 0.88 \\
\hline 37 & Tricalysia sp. & Mengkopi & Rubiaceae & 1 & 0.88 \\
\hline \multicolumn{2}{|r|}{ Total } & & & 113 & 100.00 \\
\hline
\end{tabular}

Pada lokasi ini terdapat juga jenis rotan dari jenis Calamus juga terdapat jenis Bambusa yang merupakan vegetasi penyusun hutan. Pada daerah hutan primer 2 didapatkan sebanyak 24 jenis pohon dari 15 suku. Beberapa jenis pohon yang mendominasi di lokasi ini antara lain dari Marga Ficus, dari Suku Arecaceae antara lain jenis Areca, Arenga dan Figafeta serta dari Marga Adinandra dan Palaquium. Di lokasi ini juga masih ditemukannya jenis rotan dari Marga Calamus yang juga sebagai vegetasi penyusun di hutan primer.

\subsection{Hutan Sekunder}

Jumlah jenis pohon yang ditemukan pada hutan sekunder sebanyak 28 jenis, 97 individu dan 18 suku (Tabel 2).

Tabel 2. Jenis pohon yang ditemukan pada hutan sekunder di Gunung Ambang, Sulawesi Utara 


\begin{tabular}{|c|c|c|c|c|c|}
\hline No & Nama jenis & Nama lokal & Suku & $\sum$ individu & $\%$ \\
\hline 1 & Adinandra celebica & Adinandra & Theaceae & 1 & 1.03 \\
\hline 2 & Adinandra sp. & Topad & Theaceae & 4 & 4.12 \\
\hline 3 & Agathis sp. & Toayab & Araucariaceae & 1 & 1.03 \\
\hline 4 & Aleurites moluccana & Kemiri & Euphorbiaceae & 2 & 2.06 \\
\hline 5 & Areca cetachu & Pinang & Arecaceae & 7 & 7.22 \\
\hline 6 & Areca vestiaria & Pinang yaki & Arecaceae & 1 & 1.03 \\
\hline 7 & Arenga pinnata & Pohon Aren & Arecaceae & 6 & 6.19 \\
\hline 8 & Calamus sp. & Rotan & Arecaceae & 1 & 1.03 \\
\hline 9 & Calliandra callothyrus & Kaliandra & Caesalpiniaceae & 1 & 1.03 \\
\hline 10 & Cinnamomum burmannii & Kayu Manis & Lauraceae & 3 & 3.09 \\
\hline 11 & Cyathocalyx sp & Durian Hutan & Bombaceaea & 2 & 2.06 \\
\hline 12 & Cyntandrasp. & Monanow & Gesneriaceae & 2 & 2.06 \\
\hline 13 & Dillenia serrata & Dangin & Dilleniaceae & 3 & 3.09 \\
\hline 14 & Elmerilia ovalis & Cempaka & Magnoliaceae & 8 & 8.25 \\
\hline 15 & Endospermum pelatum & Mapopo & Euphorbiaceae & 1 & 1.03 \\
\hline 16 & Ficus sp. & Beringin & Moraceae & 5 & 5.15 \\
\hline 17 & Ficus variegata & Aga Hutan & Moraceae & 3 & 3.09 \\
\hline 18 & Laportea sp & Sosoro Hutan & Urticaceae & 4 & 4.12 \\
\hline 19 & Myristica fatua & Pala hutan & Myristicaceae & 4 & 4.12 \\
\hline 20 & Nephelium $s p$ & Rambutan Hutan & Sapindaceae & 1 & 1.03 \\
\hline 21 & Palaquium obovatum & Lungkap & Sapindaceae & 2 & 2.06 \\
\hline 22 & Palaquium obtusifolium & Nantu & Sapindaceae & 5 & 5.15 \\
\hline 23 & Pometiasp. & Matoa Hutan & Sapindaceae & 1 & 1.03 \\
\hline 24 & Pterocarpus indicus & Linggua Hutan & Fabaceae & 2 & 2.06 \\
\hline 25 & Pterospermum celebecum & Bayuk & Sterculiaceae & 4 & 4.12 \\
\hline 26 & Saurauia sp. & Pasi & Actinidiaceae & 2 & 2.06 \\
\hline 27 & Sloetia minahassae & Tempiris & Moraceae & 5 & 5.15 \\
\hline \multirow[t]{2}{*}{28} & Spondias pinnata & Uribat & Anacardiaceae & 1 & 1.03 \\
\hline & Total & & & 97 & 100.00 \\
\hline
\end{tabular}

Jenis yang dominan pada habitat ini adalah Elmerilia ovalisdari suku Magnoliaceae. Pada plot satu di hutan sekunder diperoleh sebanyak 20 jenis pohon dari 15 suku.. Suku Arecaeae mendominasi jenis pohon di lokasi ini antara lain dari marga Areca, Arenga, dan Figafetta serta dari marga Ficus, Adinandra dan Elmerilia. Jenis rotan masih juga ditemukan di lokasi ini yaitu dari marga Calamus, ini menandakan bahwa jenis rotan merupakan salah satu tumbuhan yang menyusun vegetasi ini selain semak dan perdu. Pada daerah hutan sekunder 2 didapatkan sebanyak 22 jenis pohon dari 17 suku. Jenis pohon yang mendominasi antara lain dari marga Elmerilia, Sloetia dan dari suku Arecaceae yaitu marga Areca dan Figafetta.

Perbedaaan tipe habitat menyebabkan perbedaan dalam jumlah jenis dan suku dari pohon yang ditemukan di Hutan. Pada hutan primer memiliki jumlah jenis lebih banyak dibandingkan dengan hutan sekunder, demikian juga halnya dengan jumlah suku dan jumlah individu pohon yang ditemukan. Halini disebabkan karena perbedaan ketinggian tempat, suhu, dan pengaruh gangguan manusia. Hal ini mendukung pernyataan yang dikemukakan oleh Mansur (2003) meyatakan bahwa vegetasi alami yang tumbuh di daerah tertentu bergantung pada berbagai faktor seperti, kimia tanah, air tanah, iklim, tinggi di atas permukaan laut, jarak dari laut, dan jarak dari daerah yang mempunyai kondisi serupa.

Perbedaan jumlah jenis pohon antara hutan primer dan hutan sekunder juga disebabkan oleh tingkat gangguan terhadap hutan tersebut. Gangguan terhadap hutan yang berupa penebangan pohon akan mengakibatkan terbukanya tajuk pohon. Terbukanya tajuk pohon akan mengakibatkan terjadinya perubahan faktor lingkungan seperti suhu udara, penguapan, kelembaban dan intensitas cahaya matahari pada ekosistem hutan tersebut (Indrawan 2000).

\section{Kesimpulan}

Berdasarkan hasil yang didapat maka dapat disimpulkan bahwa jenis pohon penyusun hutan Gunung Ambang terdiri dari 38 jenisyang termasuk dalam 22 suku. Pohon-pohon yang menyusun vegetasi pada hutan primer terdiri dari 37 jenis dan 22 suku. Pada hutan sekunder tersusun dari 28 jenis dan 18 suku. Jenis pohon yang paling mendominasi di setiap lokasi pengamatan adalah dari suku Magnoliaceae dan Arecaceae.

\section{Daftar Pustaka}

BKSDA SULUT. 2009. Buku Informasi Kawasan Konservasi. Manado. 
Cronquist, A. 1981. An Intergrated System of Classification of Flowering Plants. Colombia University Press. New York.

Ewusie, J. Y. 1990. Pengantar Ekologi Tropika. Terjemahan oleh Usman Tanuwidjaja. Institut Teknologi Bandung Press, Bandung.

Indrawan A. 2000. Perkembangan Suksesi Tegakan Hutan Alam Setelah Penebangan Dalam Sistem Tebang Pilih Tanam Indonesia. Disertasi. Bogor:IPB.
Koorders, S.H. 1922. Flora van N.O Celebes. INHOUD.

Mansur, M. 2003. Analisis vegetasi hutan di desa Salua dan Kaduwaa Taman Nasional Lore Lindu, Sulawesi Tengah. J.Tek.Ling., P3TL-BPPT. 4 (1): 1 - 7 WCS SULUT. 2007. Peta Cagar Alam Gunung Ambang. Manado.

Withmore, T. C. 1998. Tropical Rain Forest of the Far East. Clarendon Press. Oxford, New York. 